\title{
Long term effects of early adversity on cognitive function
}

\author{
M Richards, M E J Wadsworth
}

Arch Dis Child 2004;89:922-927. doi: 10.1136/adc.2003.032490

\begin{abstract}
See end of article for authors' affiliations

.....................

Correspondence to: Dr M Richards, MRC National Survey of Health and Development, Royal Free \& University College Medical School, University College London, Department of Epidemiology \& Public Health, Gower Street Campus, 1-19 Torrington Place, London WCIE 6BT, UK; m.richards@ucl.ac.uk
\end{abstract}

Accepted 29 January 2004

\begin{abstract}
Aims: To investigate long term effects of early adverse circumstances on cognitive function.
Methods: Associations between early material home circumstances, parental divorce, maternal management and understanding, and cognitive function in childhood, adolescence, and adulthood were analysed using multiple linear regression, controlling for sex, parental SES, and birth order in 1339 males and females from the MRC National Survey of Health and Development.

Results: Early adverse circumstances were strongly associated with lower cognitive ability in childhood and adolescence, and were detectable on measures of verbal ability, memory, and speed and concentration in midlife. However, these long term effects were mostly explained by the effects of adversity on childhood or adolescent cognitive ability or by differences in educational attainment and adult social class. An exception was the effect of poor material home conditions on visual search speed at 53 years, which was maintained after controlling for adolescent ability, as well as further control for educational attainment, adult social class, physical growth, cigarette smoking, and affective state. There was no evidence of more rapid decline in memory and psychomotor function across middle age in those exposed to early adversity.

Conclusions: The effect of early adversity on cognitive function tracks across the life course at least as far as middle age, although there was little evidence from this study of effect amplification over this interval. Nevertheless, in view of the persistence of child poverty in the industrialised world, these findings give cause for concern.
\end{abstract}

$\mathrm{T}$ here is little doubt that early adverse circumstances are associated with poor cognitive development. Evidence from studies in the early twentieth century suggests that extreme poverty of the environment can lead to progressive deterioration in ability. ${ }^{1}$ Consistent with this, an association between poor material home conditions and cognitive disadvantage, has been reported in the British 1946 birth cohort, independently of social class. ${ }^{1}$

Usually psychosocial factors have been put forward to explain these associations; Douglas, for example, suggested that this was the result of poor school environment and low parental concern for the child's education. ${ }^{1}$ It may be, however, that the emotional aspects of such adversity are important, as suggested by findings that parental divorce is associated with poorer cognitive development ${ }^{2}$ and with lower educational attainment. ${ }^{3}$

The most widely discussed biological basis for these effects is the glucocorticoid cascade hypothesis, where chronic stress evokes persistent hyperactivity of the hypothalamic-pituitary-adrenal (HPA) axis, ${ }^{45}$ leading to hypercortisolaemia and associated atrophy of the hippocampus, an important neural substrate for learning and memory. ${ }^{6-9}$ There is insufficient information, however, about such long term effects in humans, an issue of potential clinical importance since cognitive impairment can lead to clinically significant decline in later life. ${ }^{10} 11$

We therefore use childhood and adult cognitive measures from a national birth cohort study, first to explore the length of the life course over which developmental effects may be detected, and second to compare evidence for the biological and the psychosocial explanations for such effects. We have examined cognitive function from ages 8 to 53 years, and its change in childhood, adolescence, and adulthood, in relation to three markers of early adversity, namely material home conditions, maternal care, and the experience of parental divorce.

\section{METHODS}

\section{Study sample}

Participants comprised the study population of the MRC National Survey of Health and Development (NSHD), also known as the British 1946 birth cohort $(n=5362$ at commencement), and initially consisting of all children of non-manual and agricultural workers and a random sample of one in four of manual workers selected from all single and legitimate births that occurred in England, Scotland, and Wales during one week in March 1946. ${ }^{12}$ The cohort has been studied on 21 occasions between birth and age 53 years, when information about sociodemographic factors and medical, cognitive, and psychological function was obtained by interview and examination. This occurred most recently in 1999 at age 53 when sample size was 3035. At this time the cohort was shown still to be a representative sample, in most respects, of the UK population legitimately and singly born in the immediate post-war era. ${ }^{13}$ Exceptions were an overrepresentation among non-responders of the never married and the least advantaged in terms of cognitive ability, educational attainment, and social class.

\section{Early adversity variables}

Material home conditions at 4 years

An aggregate variable representing material home conditions at age 4 years was obtained by summing the following ratings, made during the home based interview by a health visitor:

- State of repair of house $(1=$ very good $)$

- Age of house ( $1=$ built post-1919)

- Crowding ( $1=$ less than 1.5 persons per room)

- Cleanliness of house ( $1=$ very clean)

- Cleanliness of survey member ( 1 = very clean $)$

- Condition of survey member's shoes ( $1=$ adequate)

- Condition of survey member's clothes ( $1=$ adequate) 
To produce a more manageable indicator variable, this total score was recoded into four categories: very good ( score $=7$ ), good $($ score $=5-6)$, modest $($ score $=3-4)$, and poor $($ score $=0-2)$. Although relatively few survey members fell into the poor category, preliminary analysis suggested that this was an important category to retain. Because some of these conditions may be associated with physical illness, itself associated with poor cognitive development, ${ }^{1}$ all analyses using this indicator variable were adjusted for presence or absence of serious illness (that is, requiring hospitalisation) up to age 5 years, not including learning disability/mental retardation.

\section{Parental divorce up to 8 years}

Because of the relatively small numbers of survey members who had experienced parental divorce or death by this age, the indicator variable was dichotomised to No versus Yes.

Maternal management and understanding at 4 years As with the material home condition variables, this was rated during the home based interview by a health visitor, and scored as among the best, average, or among the worst. Because only four mothers fell into the worst category in the sample selected for analysis (see below), these were merged with the average category. Thus the indicator variable was dichotomised to Good versus Average/Poor.

\section{Cognitive outcomes}

Age 8 years: Four tests devised by the National Foundation for Educational Research (NFER) were used, as part of an investigation into the association between cognitive ability and educational attainment: ${ }^{14}$

- Reading comprehension (selecting appropriate words to complete 35 sentences).

- Word reading (ability to read and pronounce 50 words).

- Vocabulary (ability to explain the meaning of 50 words).

- Picture intelligence, consisting of a 60 item non-verbal reasoning test.

These scores were summed to yield an aggregate representing cognitive ability at this age.

Age 15 years: Three tests were used:

- Alice Heim Group Ability Test (AH4), a 130 item timed test, with separate verbal and non-verbal sections which are summed to yield a general ability score. ${ }^{15}$ The verbal items consist of analogies, comprehension, and numerical reasoning, while the non-verbal items consist of matching, spatial analysis, and non-verbal reasoning.

- The Watts-Vernon Reading Test, a test of reading comprehension requiring the participant to select appropriate words to complete 35 sentences.

- A 47 item mathematics test, requiring the use of arithmetic, geometry, trigonometry, and algebra. As at 8 years, these scores were summed to yield an aggregate representing cognitive ability at this age.

Age 26 years: The Watts-Vernon Reading Test was readministered, with an additional 10 items of increased difficulty to avoid a ceiling effect.

Age 43 years: Three tests used in this analysis were administered at this age, reflecting a new emphasis in the study on measuring functional capacity in midlife:

- Verbal memory, assessed by a 15 word list learning task, with three learning trials and free recall at the end of each.
- Timed peg placement (overall mean of three trials for each hand, subjected to a log transformation to improve distribution).

- A timed visual search task requiring cancellation of target letters $\mathrm{P}$ and $\mathrm{W}$, embedded among non-target letters (mean of three trials).

Age 53 years: The memory and visual search speed tasks given at 43 years were repeated at 53 years. In addition, the National Adult Reading Test (NART) ${ }^{16}$ was administered, a test of verbal ability requiring participants to pronounce 50 written words.

All test scores were standardised to give a mean of 0 and a standard deviation of 1 , based on the sample with nonmissing values for each variable used in this study.

\section{Educational attainment}

The highest educational or training qualification achieved by 26 years was dichotomised into ordinary secondary qualifications ("O" levels and their training equivalents) or less, versus advanced secondary education (" $\mathrm{A}$ " levels and their equivalents) or degree level or equivalent.

\section{Background variables}

Principal covariates for all analyses were sex, paternal social class (measured according to the Registrar General), ${ }^{17}$ maternal education (those with primary or secondary education only with no formal qualifications, versus those with formal qualifications or any further education), and birth order. In addition, several potential confounders were considered in the analysis of midlife cognitive function. These were: adult leg length as a measure of physical growth, since this measure is sensitive to emotional adversity (divorce) in childhood, ${ }^{18}$ and since growth is associated with cognitive function; ${ }^{19}$ smoking at 53 years, since this is negatively associated with memory and psychomotor function; ${ }^{20}$ and affective state, since this may mediate associations between emotional adversity and cognitive function. At 53 years this was measured by the GHQ-28. ${ }^{21}$

\section{Statistics}

Multiple linear regression was used to investigate the effect of each adversity variable on the cognitive outcomes. The effect of adversity on change in cognitive ability from 8 to 15 years, and from 15 to 26 years, and on change in verbal memory and visual search speed from 43 to 53 years, was investigated by adjusting each later score for the earlier score (conditional models of change). The effect of early adversity on probability of attaining advanced educational qualifications was assessed by logistic regression. All analyses were adjusted for sex, paternal social class (entered as a categorical variable), maternal education (those with primary or secondary education only with no formal qualifications, versus those with formal qualifications or any further education), and birth order (entered as a continuous variable).

\section{RESULTS}

Sample size

The sample used for this study comprised 1339 participants with non-missing values for all variables selected. Those with any missing cognitive scores at midlife had lower cognitive scores at 8,15 , and 26 years $(p<0.001$ in each case), were more likely to have a father of manual social class $(p=0.002)$ and a mother with no educational qualifications $(\mathrm{p}<0.001)$, and were more likely to have experienced poorer material home conditions and poorer maternal skills (both $\mathrm{p}<0.001)$, although there was no association between 
Table 1 Cognitive test scores by each early adversity variable; all scores are adjusted for sex, paternal social class, maternal education, and birth order $(n=1339)$

\begin{tabular}{|c|c|c|c|c|c|c|c|c|}
\hline & n (\%) & $\begin{array}{l}\text { Ability at } \\
8 \text { years }\end{array}$ & $\begin{array}{l}\text { Ability at } \\
15 \text { years }\end{array}$ & $\begin{array}{l}\text { Ability at } \\
26 \text { years }\end{array}$ & $\begin{array}{l}\text { NART at } \\
53 \text { years }\end{array}$ & $\begin{array}{l}\text { Memory at } \\
43 \text { years }\end{array}$ & $\begin{array}{l}\text { Peg speed } \\
\text { at } 43 \\
\text { years }\end{array}$ & $\begin{array}{l}\text { Search } \\
\text { speed at } \\
43 \text { years }\end{array}$ \\
\hline \multicolumn{9}{|c|}{ Material home conditions at age 4 years } \\
\hline Very good & $366(27.3)$ & 23.54 & 41.48 & 34.64 & 35.87 & 26.28 & 4.64 & 350.22 \\
\hline Good & $569(42.5)$ & 23.54 & 40.82 & 34.69 & 35.40 & 25.58 & 4.64 & 347.09 \\
\hline Modest & $323(24.1)$ & 22.08 & 38.76 & 33.08 & 33.81 & 24.58 & 4.63 & 335.93 \\
\hline Poor & $81(6.0)$ & 19.31 & 34.00 & 29.99 & 29.95 & 22.72 & 4.64 & 316.70 \\
\hline \multicolumn{9}{|c|}{ Parental death or divorce, to age 8 years } \\
\hline No & $1292(96.5)$ & 23.15 & 40.44 & 34.23 & 35.02 & 25.52 & 4.64 & 344.22 \\
\hline Yes & 47 (3.5) & 21.42 & 36.04 & 32.45 & 33.56 & 24.54 & 4.62 & 341.35 \\
\hline \multirow{2}{*}{\multicolumn{9}{|c|}{$\begin{array}{l}\text { Maternal management and understanding at age } \\
4 \text { years }\end{array}$}} \\
\hline & & & & & & & & \\
\hline Good & 735 (54.9) & 23.96 & 41.45 & 35.01 & 36.06 & 26.11 & 4.63 & 345.39 \\
\hline Average/poor & $604(45.1)$ & 21.97 & 38.81 & 33.12 & 33.59 & 24.68 & 4.64 & 342.16 \\
\hline
\end{tabular}

missing data and likelihood of parental divorce $(\mathrm{p}=0.76)$. Table 1 shows numbers in each category of the early adversity variables, as well as mean cognitive test scores, adjusted for sex, paternal social class, maternal education, and birth order.

\section{Early adversity, cognition, and educational attainment \\ Material home conditions Cognition in childhood and early adulthood}

Table 2 shows mean differences in standardised cognitive ability scores up to early adulthood between each category of material home conditions, compared to the very good category (reference), controlling for sex, paternal social class, maternal education, birth order, and serious illness by age 5 years. There was a clear and highly significant trend for adverse home conditions to be associated with poorer ability at 8 years, as well as slower cognitive development from 8 to 15 years. There was no association, however, between home conditions and cognitive change from 15 to 26 years.

\section{Cognition in midlife}

Table 3 shows effects for material home conditions on standardised NART and verbal memory scores in midlife. There was a clear gradient between home conditions and the NART at 53 years and memory at 43 years. However, these associations were strongly reduced after adjusting for cognitive ability at 15 years, with tests for trend and the individual level comparisons below 5\% significance for both measures (not shown). The association between material home conditions and change in memory from 43 to 53 years was not significant at the $5 \%$ level.

Table 4 shows effects for material home conditions on standardised psychomotor scores. There was no association between this variable and peg placement speed. However, a clear gradient between home conditions and visual search speed at 43 years can be observed, although the gradient was not significant at the 5\% level for change in this measure from 43 to 53 years. The association with visual search speed at 43 years remained significant when further adjusted for ability at 15 years, and for educational attainment and adult social class ( $p$ for trend $=0.05$ ). This was not significantly altered by additional adjustment, in turn, for adult leg length, smoking at 53 years, or affective state at 53 years (GHQ-28).

\section{Educational attainment}

Table 5 shows that adverse home conditions were associated with decreasing probability of obtaining advanced educational qualifications, after adjustment for sex, paternal social class, maternal education, birth order, and serious illness by age 5 years. This remained the case after further adjustment for cognitive ability at 15 years.

\section{Parental divorce}

Table 2 shows the effect of parental divorce up to 8 years on cognitive ability. Those who experienced parental divorce had lower ability scores at 8 years, although this effect was of borderline statistical significance. However, those who experienced parental divorce showed significantly slower cognitive development between this age and 15 years.

Table 2 Linear regression coefficients representing associations between early adversity and standardised ability scores from childhood to early adulthood; all analyses are adjusted for sex, paternal social class, maternal education, and birth order

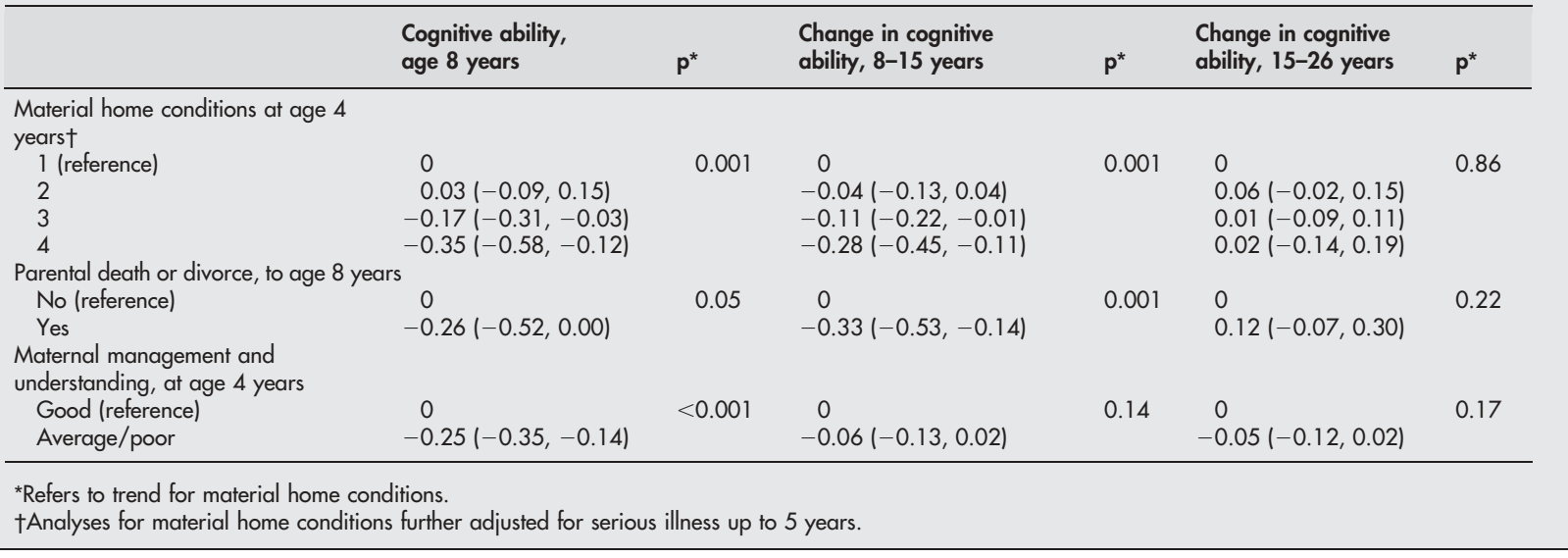


Table 3 Linear regression coefficients representing associations between early adversity and standardised NART and verbal memory scores in midlife; all analyses are adjusted for sex, paternal social class, maternal education, and birth order

\begin{tabular}{|c|c|c|c|c|c|c|}
\hline & NART at 53 years & $\mathbf{p}^{*}$ & $\begin{array}{l}\text { Verbal memory } \\
\text { at } 43 \text { years }\end{array}$ & $\mathbf{p}^{*}$ & $\begin{array}{l}\text { Change in verbal memory, } \\
43-53 \text { years }\end{array}$ & $\mathbf{p}^{*}$ \\
\hline $\begin{array}{l}\text { Material home conditions at age } 4 \text { years } † \\
1 \text { (reference) } \\
2 \\
3 \\
4\end{array}$ & $\begin{array}{l}0 \\
-0.03(-0.15,0.10) \\
-0.19(-0.33,-0.04) \\
-0.40(-0.64,-0.17)\end{array}$ & $<0.001$ & $\begin{array}{l}0 \\
-0.06(-0.19,0.06) \\
-0.22(-0.37,-0.07) \\
-0.34(-0.58,-0.10)\end{array}$ & $<0.001$ & $\begin{array}{l}0 \\
-0.05(-0.15,0.05) \\
-0.03(-0.15,0.09) \\
-0.09(-0.28,0.10)\end{array}$ & 0.42 \\
\hline $\begin{array}{l}\text { Parental death or divorce, to age } 8 \text { years } \\
\text { No (reference) } \\
\text { Yes }\end{array}$ & $\begin{array}{l}0 \\
-0.16(-0.43,0.11)\end{array}$ & 0.24 & $\begin{array}{l}0 \\
-0.15(-0.43,0.12)\end{array}$ & 0.28 & $\begin{array}{l}0 \\
-0.09(-0.31,0.13)\end{array}$ & 0.42 \\
\hline $\begin{array}{l}\text { Maternal management and } \\
\text { understanding at age } 4 \text { years } \\
\text { Good (reference) } \\
\text { Average/poor }\end{array}$ & $\begin{array}{l}0 \\
-0.22(-0.33,-0.12)\end{array}$ & $<0.001$ & $\begin{array}{l}0 \\
-0.21(-0.32,-0.10)\end{array}$ & $<0.001$ & $\begin{array}{l}0 \\
-0.10(-0.18,-0.01)\end{array}$ & 0.03 \\
\hline
\end{tabular}

*Refers to trend for material home conditions.

†Analyses for material home conditions further adjusted for serious illness up to 5 years.

NART, National Adult Reading Test.

Associations between parental divorce and cognitive change between 15 and 26 years, and cognitive function at 53 years (tables 3 and 4) were not significant at the 5\% level. Table 5 shows that parental divorce was significantly associated with lower probability of obtaining advanced educational qualifications, even after controlling for cognitive ability at 15 years.

\section{Maternal management and understanding}

Table 2 shows that average to poor maternal management and understanding was strongly associated with lower cognitive ability at 8 years, although not with cognitive change from this age to 15 years, or from 15 to 26 years. Table 3 shows that the association between this exposure and cognitive function was still detectable for the NART at 53 years, for verbal memory at 43 years, and for change in memory from 43 to 53 years. When these associations were adjusted for cognitive ability at 8 years, those for the NART and for memory change fell below $5 \%$ significance, although that for verbal memory remained significant (regression coefficient $=-0.12,95 \%$ CI $-0.22,-0.02$ ). This significance was removed, however, by further adjustment for educational attainment and adult social class. There was no effect at the $5 \%$ level between this exposure and psychomotor speed (table 4). Table 5 shows that average to poor maternal management was associated with lower probability of obtaining educational qualifications, although this association was explained by its effect on cognitive ability at 15 years.

\section{Effects of all three adversity variables together lage 53 cognitive outcomes only)}

When these analyses were repeated with all three adversity variables entered simultaneously, the effect of material home conditions on the NART and verbal memory was attenuated, although the linear trend remained significant $(p=0.03)$ in both cases. Coefficients for the association between home conditions and visual search speed remained essentially unchanged however ( $\mathrm{p}$ for trend $=0.003$ ). The effect of maternal management and understanding was slightly reduced for the NART and verbal memory by this mutual adjustment, although effects remained significant at below the $1 \%$ level in both cases. Furthermore, the association between maternal management and memory decline was essentially unaltered. Adjusted coefficients are not reported for parental divorce, since there was no unadjusted association between this exposure and any of the midlife cognitive variables.

\section{DISCUSSION}

In a nationally representative birth cohort we found that early adverse circumstances were associated with lower cognitive ability, and lower cognitive growth, in childhood, independently of social background. Adverse circumstances were also associated with lower educational attainment, as previously shown in this cohort, ${ }^{22}$ although here we show that this association was independent of cognitive ability.

The central goal of this study, however, was to investigate long term effects of early adversity on cognition. These were

Table 4 Linear regression coefficients representing associations between early adversity and standardised psychomotor scores in midlife; all analyses are adjusted for sex, paternal social class, maternal education, and birth order

\begin{tabular}{|c|c|c|c|c|c|c|}
\hline & Peg placement speed & $\mathbf{p}^{*}$ & Visual search speed & $\mathbf{p}^{*}$ & $\begin{array}{l}\text { Change in visual search } \\
\text { speed, } 43-53 \text { years }\end{array}$ & $\mathbf{p}^{*}$ \\
\hline $\begin{array}{l}\text { Material home conditions at age } 4 \text { years } \dagger \\
1 \text { (reference) } \\
2 \\
3 \\
4\end{array}$ & $\begin{array}{l}0 \\
0.01(-0.13,0.14) \\
-0.04(-0.20,0.11) \\
0.10(-0.15,0.36)\end{array}$ & 0.94 & $\begin{array}{l}0 \\
-0.02(-0.15,0.11) \\
-0.17(-0.32,-0.01) \\
-0.35(-0.60,-0.10)\end{array}$ & 0.003 & $\begin{array}{l}0 \\
-0.04(-0.15,0.08) \\
-0.02(-0.15,0.11) \\
-0.20(-0.42,0.01)\end{array}$ & 0.23 \\
\hline $\begin{array}{l}\text { Parental death or divorce, to age } 8 \text { years } \\
\text { No (reference) } \\
\text { Yes }\end{array}$ & $\begin{array}{l}0 \\
-0.12(-0.41,0.17)\end{array}$ & 0.43 & $\begin{array}{l}0 \\
-0.02 \\
(-0.31,0.26)\end{array}$ & 0.87 & $\begin{array}{l}0 \\
-0.04\end{array}(-0.28,0.20)$ & 0.74 \\
\hline $\begin{array}{l}\text { Maternal management and } \\
\text { understanding at age } 4 \text { years } \\
\text { Good (reference) } \\
\text { Average/poor }\end{array}$ & $\begin{array}{l}0 \\
0.07(-0.05,0.18)\end{array}$ & 0.24 & $\begin{array}{l}0 \\
-0.04\end{array}(-0.15,0.07)$ & 0.49 & $\begin{array}{l}0 \\
0.03(-0.06,0.13)\end{array}$ & 0.49 \\
\hline
\end{tabular}

*Refers to trend for material home conditions.

†Analyses for material home conditions further adjusted for serious illness up to 5 years. 
Table 5 Risk ratios representing associations between early adversity and probability of obtaining advanced educational qualifications; all analyses are adjusted for sex, paternal social class, maternal education, and birth order

\begin{tabular}{|c|c|c|c|c|}
\hline & $\begin{array}{l}\text { Probability of } \\
\text { advanced } \\
\text { qualifications }\end{array}$ & $\mathbf{p}^{*}$ & $\begin{array}{l}\text { Probability of advanced } \\
\text { qualifications (adjusted for } \\
\text { cognition at age } 15 \text { years) }\end{array}$ & $\mathbf{p}^{*}$ \\
\hline \multicolumn{5}{|c|}{ Material home conditions } \\
\hline 1 (reference) & 1 & $<0.001$ & 1 & $<0.001$ \\
\hline 2 & $0.75(0.55,1.01)$ & & $0.73(0.52,1.01)$ & \\
\hline 3 & $0.43(0.30,0.62)$ & & $0.47(0.31,0.72)$ & \\
\hline 4 & $0.21(0.09,0.46)$ & & $0.33(0.14,0.79)$ & \\
\hline \multicolumn{5}{|c|}{$\begin{array}{l}\text { Parental death or divorce, } \\
\text { to age } 8 \text { years }\end{array}$} \\
\hline No (reference) & & 0.001 & & 0.01 \\
\hline Yes & $0.22(0.09,0.55)$ & & $0.29(0.11,0.77)$ & \\
\hline \multicolumn{5}{|c|}{$\begin{array}{l}\text { Maternal management and } \\
\text { understanding at age } 4 \text { years }\end{array}$} \\
\hline Good (reference) & 1 & 0.03 & & 0.52 \\
\hline Average/poor & $0.75(0.58,0.97)$ & & $0.91(0.68,1.22)$ & \\
\hline
\end{tabular}

certainly detectable on measures of ability, memory, and speed and concentration in midlife, although these long term effects were mostly explained by the effects of adversity on childhood ability or educational attainment, and by adult social class. Thus while the impact of early adversity on cognition tracks at least as far as middle age, there was no evidence of amplification of this effect across the adult years. The outstanding exception was the effect of poor material home conditions on psychomotor (visual search) speed. This was maintained after controlling for adolescent ability, educational attainment, adult social class, physical growth, cigarette smoking, and affective state. Whether this particular function is sensitive to long term central effects of stress induced hypercortisolaemia can only be speculative at this time.

Three potential limitations of this study should be highlighted. First, there was a disproportionate loss to follow up of those with lower cognitive ability. This limits the generalisability of the study, and may have caused underestimation of the true effects of adversity on cognition, although we have no reason to believe that this had any impact on the pattern of associations themselves. Second, the ratings of material home conditions and maternal management and understanding, made by a health visitor, were to some extent subjective, and could therefore have been vulnerable to bias according to perceived social position. In this context it should be emphasised that associations between these variables and cognition were independent of socioeconomic status of the parents. Third, the variables representing early adversity are relatively crude, and do not indicate the precise nature of the exposure. This is particularly so for the maternal management rating, but also applies to parental divorce, which we have treated as a proxy for adversity, as parental separation per se, and single parenthood might serve today.

What are the wider implications of this study, including those for public health? Rutter stated that while extreme environmental circumstances can have "very substantial" effects on IQ, effects of variations within the normal environment are more modest. ${ }^{23}$ The present results are consistent with this position, although they suggest that early emotional adversity can have serious consequences for the future. In particular, all three types of adversity were associated with relatively low educational attainment, and for one type (suboptimal maternal management) this was a direct consequence of its effect on cognitive development.
The implications of lower educational attainment for adult socioeconomic status ${ }^{24-26}$ and health ${ }^{27}$ are well known. These results give cause for concern from a public health perspective, in view of the contemporary persistence of childhood poverty. ${ }^{28}{ }^{29}$ The identification of factors, such as parental and educational support, that mitigate the impact of early adversity on cognitive function is therefore a matter of considerable importance.

\section{ACKNOWLEDGEMENTS}

Funding for the NSHD is provided by the Medical Research Council. Data collection at 53 years was carried out by the National Centre for Social Research.

\section{Authors' affiliations}

M Richards, M E J Wadsworth, MRC National Survey of Health and Development, Royal Free \& University College Medical School, University College London, UK

\section{REFERENCES}

1 Douglas JWB. The home and the school. London: MacGibbon \& Kee, 1964.

2 Amato PR, Keith B. Parental divorce and the well-being of children: a metaanalysis. Psychol Bull 1991;110:26-46.

3 Ely M, Richards MPM, Wadsworth MEJ. Secular changes in the association of parental divorce and children's educational attainment-evidence from three British birth cohorts. J Soc Pol 1999;28:437-55.

4 Coplan JD, Andrews MW, Rosenblum LA, et al. Persistent elevations of cerebrospinal fluid concentrations of corticotropin-releasing factor in adult nonhuman primates exposed to early-life stressors: implications for the pathophysiology of mood and anxiety disorders. Proc Natl Acad Sci U S A 1996;93:1619-23.

5 Ladd CO, Owens MJ, Nemeroff CB. Persistent changes in corticotropinreleasing factor neuronal systems induced by maternal deprivation. Endocrinology 1996;137:1212-18.

6 Sapolsky RM, Krey LC, McEwen BS. The neuroendocrinology of stress and aging - the glucocortocoid cascade hypothesis. Endocr Rev 1986;7:284-301.

7 Vallee M, Maccari S, Dellu F, et al. Long-term effects of prenatal stress and postnatal handling on age-related glucocorticoid secretion and cognitive performance: a longitudinal study in the rat. Eur J Neurosci 1999; 11:2906-16.

8 Heim C, Newport DJ, Miller AH, et al. Long-term neuroendocrine effects of childhood maltreatment. JAMA 2000;284:2321.

9 Heim C, Newport DJ, Bosnal R, et al. Altered pituitary-adrenal axis responses to provocative challenge tests in adult survivors of childhood abuse. Am J Psychiatry 2001;158:575-81.

10 Jacobs DM, Sano M, Dooneief G, et al. Neuropsychological detection and characterization of preclinical Alzheimer's disease. Neurology 1995;45:957-62.

11 Masur DM, Sliwinski M, Lipton RB, et al. Neuropsychological prediction of dementia and the absence of dementia in healthy elderly persons. Neurology 1994;44: 1427-32.

12 Wadsworth MEJ. The imprint of time: childhood, history and adult life. Oxford: Clarendon Press, 1991. 
13 Wadsworth MEJ, Butterworth SL, Hardy R, et al. The life course design: an example of benefits and problems associated with study longevity. Soc Sci Med, In press.

14 Pigeon DA. Tests used in the 1954 and 1957 surveys. Appendix 1. In: Douglas JWB, ed. The home and the school. London: Macgibbon \& Kee, 1964.

15 Pigeon DA. Details of the fifteen years tests. Appendix 1. In: Douglas JWB, Ross JM, Simpson HR, eds. All our future. London: Davies, 1968.

16 Nelson HE, Willison JR. National Adult Reading Test (NART), 2nd edn. Windsor: NFER-Nelson, 1991

17 Office of Population Censuses and Surveys. Classification of occupations. London: HMSO, 1970

18 Wadsworth MEJ, Hardy R, Paul AA, et al. Leg and trunk length at 43 years in relation to childhood health, diet and family circumstances; evidence from the 1946 national birth cohort. Int J Epidemiol 2002;31:383-90.

19 Richards M, Hardy R, Kuh D, et al. Postnatal growth and cognitive function in a national UK birth cohort. Int J Epidemiol 2002;31:342-8.

20 Richards $M$, Jarvis MJ, Thompson N, et al. Cigarette smoking and cognitive decline in midlife: evidence from a prospective birth cohort study. Am J Public Health In press.
21 Goldberg DP, Hillier VF. A scaled version of the General Health Questionnaire. Psychol Med 1979;9:139-45.

22 Wadsworth MEJ, Maclean M. Parents' divorce and children's life chances. Children Youth Services Rev 1986:8:145-59.

23 Rutter M. Family and school influences on cognitive development. J Child Psychol Psychiatry 1995;26:683-704.

24 Kuh D, Wadsworth MEJ. Childhood influences on adult male earnings in a longitudinal study. Br J Sociol 1991;42:537-55.

25 Kuh D, Head J, Hardy R, et al. The influence of education and family background on women's earnings in midlife: evidence from a British national birth cohort study. Br J Sociol Educat 1997; 18:385-405.

26 Gregg P, Machin S. Childhood experiences, educational attainment and adult labour market performance. In: Vleminckx K, Smeedling TM, eds. Child wellbeing, child poverty and child policy in modern nations. Bristol: The Policy Press, 2001:129-50.

27 Ross CE, Wu C. The links between education and health. Am Soc Rev 1995;60:719-45.

28 Coleman D. Population and family. In: Halsey AH, Webb J, eds. Twentiethcentury British social trends. Basingstoke: Macmillan, 2000:27-93.

29 Atkinson AB. Distribution of income and wealth. In: Halsey AH, Webb J, eds. Twentieth-century British social trends. Basingstoke: Macmillan, 2000:348-81.

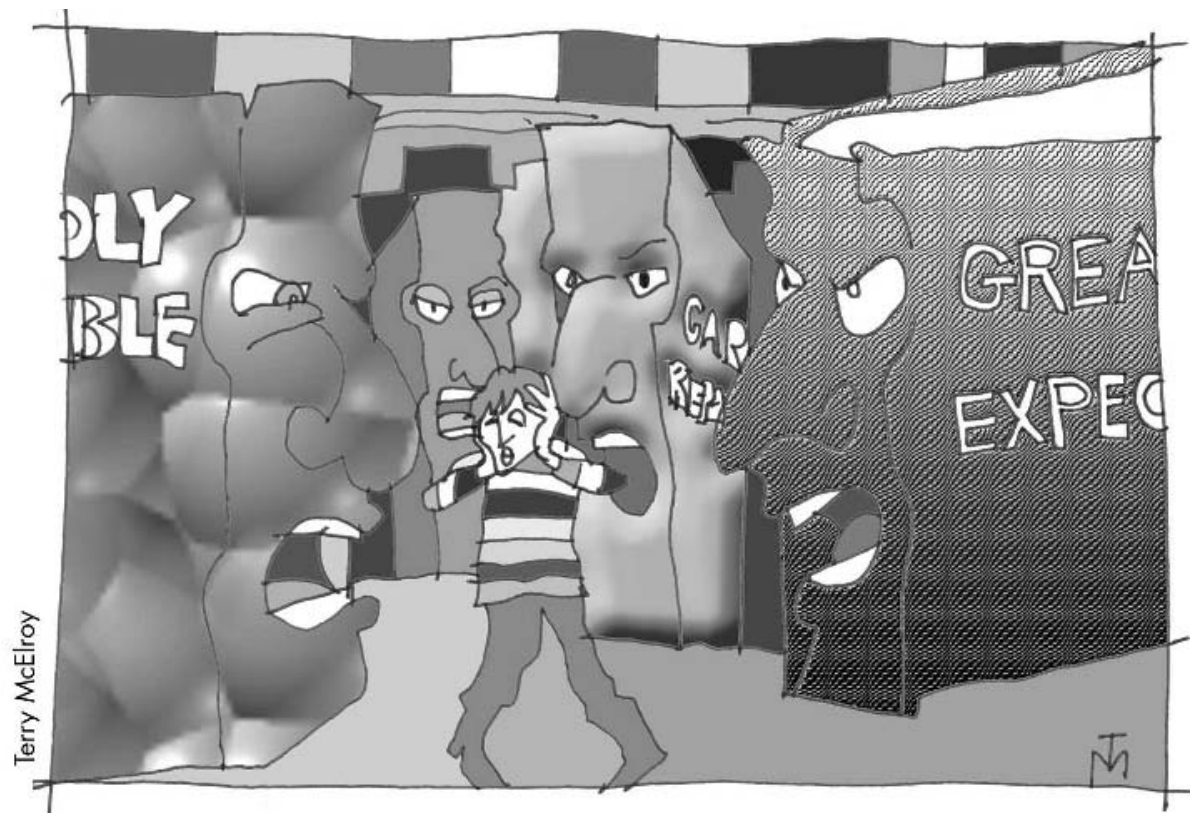

